Res., Soc. Dev. 2019; 8(3):e3083790

ISSN 2525-3409 | DOI: http://dx.doi.org/10.33448/rsd-v8i3.790

\title{
Compreensão do discurso do professor pelo aluno do ensino médio na sala de aula de
} matemática

\section{Communication in the middle school classroom: how the student understands the math teacher's speech}

Comprensión del discurso del profesor por el alumno de la escuela secundaria en el aula de matemáticas

\author{
Jailson Lourenço de Pontes \\ ORCID: https://orcid.org/0000-0001-7619-556X \\ Universidade Estadual da Paraíba, Brasil \\ E-mail: jail21.jlo@gmail.com \\ Daiana Estrela Ferreira Barbosa \\ ORCID: https://orcid.org/0000-0003-0213-5331 \\ Universidade Estadual da Paraíba, Brasil \\ E-mail: daiana.estrela@hotmail.com \\ Pedro Lucio Barboza \\ Universidade Estadual da Paraíba, Brasil \\ E-mail: plbcg@yahoo.com.br
}

Recebido: 22/11/2018 | Revisado: 07/12/2018 | Aceito: 20/12/2018 | Publicado: 21/12/2018

\section{Resumo}

Este estudo tem o objetivo de analisar como o aluno do ensino médio compreende o discurso do professor de matemática na sala de aula. Adotamos uma abordagem qualitativa, cujos dados foram obtidos por meio de gravações em vídeo das aulas e das entrevistas gravadas também em vídeo de dois professores de escolas públicas. Na análise dos dados foram utilizados elementos da teoria da linguagem de Bakhtin. Neste estudo, não podemos afirmar que de fato ocorreram situações em que os professores tenham utilizado um gênero discursivo provocando o aluno para interações com os colegas e a participação na sala de aula, porém, podemos afirmar que em alguns momentos ocorrem situações que podem trazer implicações no processo de compreensão dos alunos. É possível afirmar que quando um dos professores realiza um discurso buscando fazer comparações, mesmo relativizando o rigor da linguagem matemática, ocorre o favorecimento da compreensão do discurso do professor pelo aluno. Observamos também que a fala de um professor interlocutor da pesquisa sugere que o mesmo 
não compreende o próprio discurso, pela forma que o realiza.

Palavras-Chave: Ensino e aprendizagem. Ensino de matemática. Interações.

\begin{abstract}
This study aims to analyze how the high school student understands the speech of the mathematics teacher in the classroom. We adopted a qualitative approach, whose data were obtained through video recordings of the classes and videotaped interviews of two public school teachers. In the data analysis, elements of Bakhtin's theory of language were used. In this study, we can not affirm that in fact there were situations in which teachers used a discursive genre provoking the student to interact with colleagues and participation in the classroom, however, we can affirm that in some moments situations occur that may implications in the students' comprehension process. It is possible to affirm that when one of the teachers makes a speech seeking to make comparisons, even relativizing the rigor of the mathematical language, there is the favoring of the comprehension of the teacher's discourse by the student. We also observe that the speech of a research interlocutor suggests that the researcher does not understand the discourse itself, by the way it performs it.
\end{abstract}

Keywords: Teaching and learning. Mathematics teaching. Interactions.

\title{
Resumen
}

Este estudio tiene el objetivo de analizar cómo el alumno de la enseñanza media comprende el discurso del profesor de matemáticas en el aula. Adoptamos un enfoque cualitativo, cuyos datos fueron obtenidos por medio de grabaciones en video de las clases y de las entrevistas grabadas también en video de dos profesores de escuelas públicas. En el análisis de los datos se utilizaron elementos de la teoría del lenguaje de Bakhtin. En este estudio, no podemos afirmar que de hecho ocurrieron situaciones en que los profesores hayan utilizado un género discursivo provocando al alumno para interacciones con los colegas y la participación en el aula, sin embargo, podemos afirmar que en algunos momentos ocurren situaciones que pueden traer implicaciones en el proceso de comprensión de los alumnos. Es posible afirmar que cuando uno de los profesores realiza un discurso buscando hacer comparaciones, incluso relativizando el rigor del lenguaje matemático, ocurre el favorecimiento de la comprensión del discurso del profesor por el alumno. Observamos también que el habla de un profesor interlocutor de la investigación sugiere que el mismo no comprende el propio discurso, por la forma que lo realiza.

Palabras clave: Enseñanza y aprendizaje. Enseñanza de matemáticas. Interacciones. 


\section{Introdução}

No Brasil, o estudo do discurso é um tema ainda é pouco explorado nos cursos de licenciatura em matemática, assim como pelas pesquisas em educação matemática, diferentemente de alguns países, onde o tema tem recebido uma maior atenção dos pesquisadores, além de também integrar programas de formação continuada de professores (PONTE et al., 2007; JANSEN, 2008).

Bakhtin (2003, p. 274) expressa o discurso como sendo "a palavra indefinida riétch ('fala, [discurso]'), que pode designar linguagem, processo de discurso, ou seja, o falar, um enunciado particular ou uma série indefinidamente longa de enunciados e um determinado gênero discursivo". Desse modo, o discurso pode transmitir a forma analítica do que está sendo afirmado enquanto expressão que não caracteriza apenas o objeto do discurso, mas também o próprio falante: sua maneira de falar, seu estado de espírito expresso não no conteúdo, mas nas formas do discurso, por exemplo, a fala entrecortada, a escolha da ordem das palavras ou a entoação.

Para o autor supracitado, o discurso se constrói entre, no mínimo, dois interlocutores. Para esse autor, o discurso mantém relações com outros discursos e, para que o mesmo seja compreendido, deve ser compreendido também o seu contexto.

A linguagem matemática praticada e o discurso realizado pelo professor implicam fortemente no processo de comunicação em sala de aula. O discurso empregado pelo professor de matemática pode oferecer importantes elementos para sua atuação, deste modo, esse discurso pode interferir na compreensão dos alunos. Então, também torna-se fundamental analisar as interações entre o professor e os alunos na sala de aula.A comunicação entre professor e aluno exige alguns cuidados para que a meta do professor, que é promover a aprendizagem por parte do aluno, seja atingida. Como exemplo, podemos citar o modo como a participação do aluno será explorada pelo professor, pois essa manifestação deve partir do aluno, se for exigida pelo professor, como sendo uma obrigação o aluno falar, irá causar uma surpresa no aluno, tornando a sua fala um vazio.

De acordo com Pimm;

No caso desta manifestação falada pelo aluno e iniciada pelo professor, o "outro" (a quem o aluno se dirige) é o professor, e o aluno pode não ter algo para dizer. [...] A motivação para falar é externa e o 
Res., Soc. Dev. 2019; 8(3):e3083790

ISSN 2525-3409 | DOI: http://dx.doi.org/10.33448/rsd-v8i3.790

fato de fazê-lo em público pode suscitar consideráveis pressões, em especial quando os alunos são chamados de forma individual, pelo nome (PIMM, 1990, p. 57).

Em relação à linguagem utilizada na sala de aula, é possível observar que existem dois tipos: a linguagem matemática, que faz uso dos símbolos e expressões matemáticas, e a linguagem natural, que é a linguagem que costumamos usar diariamente para realizar a comunicação com as pessoas. A linguagem natural pode ser classificada como linguagem formal, utilizada quando não há familiaridade entre os interlocutores da comunicação ou em situações que requerem uma maior seriedade, caracterizando-se pela utilização rigorosa das normas gramaticais, e a linguagem informal, que é utilizada quando existe familiaridade entre os interlocutores da comunicação ou em situações de descontração que se caracterizam pela utilização de gírias, palavras de teor inapropriado, palavras inventadas, gestos etc.

Os alunos dominam, normalmente, mais a linguagem natural informal, pois esta é a que eles mais utilizam no dia-a-dia, com amigos, familiares, colegas da escola, etc. Partindo disso, se faz necessário que o professor realize uma combinação entre a linguagem natural informal e a linguagem matemática, pelo fato de muitas vezes os alunos não conseguirem compreender o discurso do professor ao utilizar a linguagem matemática, então o professor deve tentar realizar o seu discurso na linguagem natural, que é a mais dominada pelos alunos, de modo que ele introduza aspectos da linguagem matemática dentro da linguagem natural.

Na educação matemática, buscar formas de comunicação apropriadas na sala de aula é algo desejável, porém é preciso considerar que na sala de aula existe uma relação estável que legitima o discurso do professor.

Entendemos que a palavra discurso abrange as mais diversas formas de manifestação da linguagem e da comunicação verbal. De acordo com Almeida (2016), além dos gêneros de discurso que são próprios da Matemática, o professor pode fazer uso, em sala de aula, de outros gêneros que pertençam ao cotidiano dos alunos, como panfletos de lojas, tabelas nutricionais, classificados de jornais, extratos bancários, entre outros.

Neste estudo, consideramos discurso como sendo ações que se manifestam de formas variadas, por meio de realizações gestuais, escritas ou orais da linguagem, em particular, as ações que professores e alunos realizam no ambiente da sala de aula. Podemos então dizer que o discurso refere-se ao modo como os significados são atribuídos e trocados pelos interlocutores em um processo de diálogo.

Como o discurso do professor é compreendido pelo aluno? Esta é uma questão em 
aberto, que gostaríamos de responder. Vamos a descrição feita por Bakhtin para o significado de compreensão. Bakhtin apresenta compreensão como um processo em que as enunciações do ouvinte entram em contato com as enunciações do falante, assim:

Compreender a enunciação de outrem significa orientar-se em relação a ela, encontrar o seu lugar adequado no contexto correspondente. A cada palavra da enunciação que estamos em processo de compreender, fazemos corresponder uma série de palavras nossas, formando uma réplica. Quanto mais numerosas e substanciais forem, mais profunda e real é a nossa compreensão (BAKHTIN, 2006, p. 136-137).

Sendo assim, o ouvinte a cada palavra da enunciação ou do discurso que está buscando compreender, formula um conjunto de palavras dando uma interpretação particular para as mesmas. Portanto, a compreensão é uma forma de diálogo, compreender é opor à palavra do locutor uma contra palavra. Não significa dizer que compreender é fazer oposição a um determinado discurso, mas usar o discurso do outro para formular um discurso resposta

Consideramos que o aluno compreende o discurso do professor de matemática quando ele orienta-se em relação a esse discurso, contrapondo a ele significados já elaborados em suas experiências cotidianas. De outra maneira, a compreensão do aluno é uma resposta a um discurso matemático por meio de outro discurso matemático. Em sala de aula o professor apresenta uma série de discursos, aos quais os alunos reagem de acordo com a compreensão obtida em cada um.

O discurso proferido pelo professor de matemática tem intenções, significados; para compreender esse discurso, o contexto onde ele é proferido precisa ser levado em consideração. A compreensão não implica apenas a compreensão da linguagem, mas também as intenções que não são explicitadas.

Considerando o que diz Bakhtin (2006) no conceito de compreensão acima, afirmamos que o aluno a cada discurso do professor de matemática que está em processo de compreender, faz corresponder uma série de palavras suas, formando uma réplica ou uma resposta ao discurso do professor. Nessa perspectiva de compreensão, entendemos que o aluno compreende o discurso não apenas quando se posiciona em relação ao discurso do professor, mas atribui significado ao discurso do professor para construir o seu discurso, ou seja, argumentar sobre o discurso do professor com suas próprias palavras.

Os discursos realizados por professores e alunos refletem e sugerem como ocorrem as 
interações e a aprendizagem, de tal forma que compreender esses discursos e essas interações é essencial. Para conhecer como se dá a aprendizagem matemática do aluno é fundamental analisar o que acontece na comunicação entre aluno e professor na sala de aula, para que assim seja possível identificar os aspectos que podem ser melhorados na comunicação entre ambos.

Nesta pesquisa analisamos como o aluno do ensino médio compreende o discurso do professor na sala de aula de matemática e adotamos como perspectiva para a análise dos dados uma abordagem qualitativa. Esse tipo de abordagem é definida por Denzin e Lincoln (2005, p. 3) como, "uma atividade situada que localiza o observador no mundo. É constituída por um conjunto de interpretações, matérias práticas que tornam o mundo visível. Estas práticas transformam o mundo". A pesquisa qualitativa pode ser caracterizada como uma tentativa de compreender de forma detalhada os significados e características das situações observadas pelo pesquisador em relação aos interlocutores da pesquisa.

\section{Discursos, diálogos e interações na sala de aula de matemática}

Há diversas pesquisas que guardam certa similaridade. Os estudos sobre comunicação em sala de aula de matemática, linguagem do professor, interações discursivas ou influências da linguagem e da comunicação em sala de aula de matemática, têm elementos que se aproximam. Não é nossa preocupação analisar tais aproximações ou similaridades. O nosso interesse é conhecer como o aluno do ensino médio compreende o discurso do professor de matemática na sala de aula.

Sabemos que os alunos sentem diversas dificuldades para aprender matemática, dificuldades estas que, de certa forma, causam incômodo no professor, assim, o mesmo tem buscado estratégias e metodologias que possibilitem garantir o aprendizado do aluno. Deparados com estas dificuldades, pesquisadores da educação matemática procuram contribuir com pesquisas que objetivem minimizar o insucesso do aluno na educação básica.

Afinal, o que causa o insucesso do aluno na escola, principalmente na disciplina de matemática? São as metodologias utilizadas em sala de aula ou a má formação de alguns professores? Ou isto tem alguma coisa relacionada com a comunicação? Será que o discurso que o professor produz na sala de aula não favorece para a aprendizagem do aluno? Muitas outras perguntas podem ser formuladas.

As formas de comunicação, o modo como ocorre, nem sempre favorecem a aprendizagem. Buscar formas de comunicação apropriadas na sala de aula é algo desejável na 
educação matemática. Entretanto, é preciso considerar que na sala de aula existe uma relação já consolidada que legitima o discurso do professor. Para Fadel (2008, p. 119), “o poder na sala de aula de matemática não é uma questão puramente externa, nem somente interna: de início, ele se dá pelas posições definidas socialmente e sua manutenção depende de uma dura negociação durante a interação discursiva”. Acrescente-se ainda, que o discurso do professor é privilegiado em relação ao discurso do aluno, a partir do fato de que o professor é reconhecido como detentor do conhecimento matemático (FIORENTINI, 1995).

Alguns autores (DAVIDSON, 1990; COBB, 1999; CARVALHO, 2009) consideram as interações discursivas como sendo essenciais na sala de aula de matemática. Além disso, devem ser entendidas na sua relação com contextos histórico-sociais e com as ferramentas culturais disponíveis por uma comunidade. Dependendo de como ocorram, as interações entre professor e alunos e entre os próprios alunos podem contribuir para a compreensão do discurso do professor pelos alunos.

Muitas vezes as interações podem ocorrer de um modo que os discursos não são compreendidos. Os diálogos em sala de aula proporcionam formas de interação que resultam em mudança no desenvolvimento dos alunos, mas nem sempre isso acontece, assim, quais são as situações de interações que podem favorecer para estas mudanças, ou melhor, como o discurso do professor na sala de aula de matemática pode implicar para a compreensão dos alunos?

Fazer uma análise do que acontece na comunicação entre professor e alunos na sala de aula é algo fundamental para que se possa conhecer como ocorre a aprendizagem dos alunos, além de ser possível identificar os aspectos que podem ser melhorados nessa comunicação, pois o discurso que o professor de matemática realiza em sala de aula oferece elementos importantes para a sua atuação, deste modo, esse discurso é um fator que interfere na compreensão dos alunos.

Pesquisas de White (2003, apud Monteiro, 2014) mostram que os alunos não aprendem matemática quando ficam passivos em sala de aula, ou seja, apenas ouvindo o discurso do professor, por isso, surge a necessidade de diálogos e interações entre alunos e professores para que haja compreensão por parte dos alunos.

Cobb et al. (1997, apud SANTOS et al., 2017, p. 4) consideram que a participação dos alunos no discurso pode apoiar para a aprendizagem dos mesmos. Para os autores, o discurso é, teoricamente, uma construção útil na medida em que sugere possíveis relações entre o discurso de sala de aula e o desenvolvimento matemático. Mas eles observam que dar início e orientar o desenvolvimento do discurso exige bom senso e julgamento por parte do professor, 
pois isto ajuda a esclarecer alguns aspectos do papel que ele desempenha. Assim, os autores afirmam que o professor desempenha um papel antecipado na orientação e desenvolvimento do discurso, de modo simultâneo destacam que o discurso é uma realização da interação em sala de aula e que os estudantes devem contribuir de forma ativa para o seu desenvolvimento.

White (2003, apud SANTOS et al., 2017, p. 4) afirma que "o discurso permite que os alunos se concentrem em decisões e raciocínio, possibilita aos professores uma reflexão sobre a compreensão dos alunos e permite estimular o raciocínio matemático". O mesmo também comenta que o discurso em sala de aula exige que o professor faça com que todos os alunos se envolvam no discurso, monitorando a participação dos alunos e os encorajando a participar do debate.

Para Freitas e Fiorentini (2008, apud BARBOZA; RÊGO; BARBOSA, 2014, p. 51), "o discurso do professor, na sala de aula de matemática, pode ser realizado de diversas formas, expressando o pensamento e ideias tanto por meio da linguagem oral como também escrita, simbólica, tecnológica ou pictórica”. Assim, podemos dizer que, os discursos e as linguagens podem ser usados tanto por professores como também por alunos, de maneiras distintas, para que possam elaborar argumentos e perguntas, representar e informar, seja de modo gestual, verbal ou escrito. Caso sejam estudadas e analisadas, essas diferentes formas de discursos podem contribuir para uma melhor comunicação em sala de aula, além de ajudar a esclarecer como os alunos compreendem o discurso do professor.

O estudo do discurso do professor de matemática em sala de aula pouco aparece nos periódicos nacionais da área. Em um estudo de Monteiro e Nacarato (2004) são discutidas concepções presentes nas falas de alunos dos cursos de licenciatura em matemática e pedagogia a favor da inclusão do saber cotidiano no contexto escolar. O estudo tomou como referência um questionário aberto respondido por futuros professores de matemática.

O estudo de Monteiro e Nacarato (2004) apresenta como conclusão que as discussões presentes nas relações entre saberes: escolar e cotidiano indicam uma diversidade de interpretações que aparecem nos discursos dos futuros professores. A outra conclusão mais forte é que foi constatada superficialidade na discussão do significado do saber cotidiano e também do saber escolar e que essa vulgarização gerou um falso consenso de que a inserção do saber cotidiano no processo de escolarização é o caminho para resolver a maior parte dos problemas presentes na educação atual.

Innes (2007) fez um estudo em que analisou a qualidade do discurso na aprendizagem. O estudo constatou uma baixa incidência de diálogo de alta qualidade, em termos de comunicação dialógica, elaboração e construção de ideias em sala de aula pelos alunos. O 
pesquisador, que utiliza a palavra diálogo diferente do proposto por Bakhtin, apontou em seus estudos a necessidade de futuras investigações centradas nos aspectos socioculturais da aprendizagem para responder a questões da seguinte ordem: Quais as ligações diretas e indiretas entre a qualidade dos diálogos em sala de aula e a qualidade da aprendizagem? Como os diálogos em sala de aula se relacionam com outras formas de discurso?

Para Santos (2009, p. 118)), “a ação e os discursos praticados pelo professor quando ensina matemática, decorrem do seu conhecimento e o modo de ver a matemática, de como enxerga e escuta o aluno". Isto significa que no processo de ensino e aprendizagem da matemática, os aspectos linguísticos precisam ser considerados inseparáveis dos aspectos conceituais, para que assim ocorra a comunicação e a aprendizagem. Deste modo, podemos dizer que boa parte das dificuldades para a aprendizagem matemática decorrem da interferência entre as diversas formas de expressão, entre a representação dos símbolos e de seus significados e entre expectativas do professor e seus alunos na sala de aula.

Em pesquisas realizadas encontramos resultados diferentes em relação aos aspectos das interações nas aulas de matemática. Por exemplo, Vaccari (2007) e Martin, Towers e Pirie (2006) afirmam como se as interações fossem algo definitivo para a caracterização da aprendizagem, isto é, bastaria que ocorressem as interações e estaria assegurada a aprendizagem. Diferente disso, Sfard e Kieran (2001) e Watson e Chik (2001) apresentam resultados que mostram não ser suficiente ocorrer interações para garantir a aprendizagem.

O conteúdo temático e a prática (que são próprios de cada aula) são características do discurso na sala de aula de matemática. Estes podem sofrer influências ou serem limitados pelo contexto social e cultural a que está sujeitada cada sala de aula e até mesma cada escola. Ao utilizar em seu discurso formas gramaticais oficiais com alunos de culturas diversificadas, que fazem uso de uma linguagem diferente da institucionalizada pela escola, o professor pode gerar dificuldades na comunicação e, como consequência, implicar em problemas para a aprendizagem dos mesmos. Surge então a necessidade de o professor realizar um discurso que seja compreendido pelos alunos. No caso da matemática, este discurso também deve levar em consideração a linguagem contida na disciplina juntamente com a linguagem padrão, que é exigida pela norma culta, e também as diversas linguagens dos diferentes tipos de culturas que se encontram presentes dentro da sala de aula.

A matemática ensinada na escola, de certo modo, parece estar distante da compreensão dos alunos, distanciamento este que é um dos fatores do fracasso no ensino da disciplina. Associar a matemática ensinada na escola com assuntos cotidianos seria um meio de prender a atenção do aluno, de forma com que ele possa compreender mais claramente a matemática 
da escola. O professor deve buscar maneiras de facilitar a compreensão dos alunos e realizar um discurso que favoreça a aprendizagem e a compreensão dos mesmos, considerando seus conhecimentos prévios, aqueles que adquirimos no nosso cotidiano, seja na maneira de pensar, se expressar, falar ou até mesmo no agir. A comunicação em sala de aula deve ser clara, o máximo possível, para que haja entendimento significativo entre ambos.

Para que a escola seja um ambiente que favoreça as interações entre os alunos e professor, se faz necessário que os mesmos desenvolvam significados aos fenômenos e aos símbolos específicos da cultura deste ambiente, cultura esta em que os alunos serão inseridos e tem o professor como o seu representante. Espera-se que o aluno desenvolva hábitos de argumentar, refletir e formas de pensar que os incentivem a participarem e a contribuírem ativamente da sua renovação.

Segundo Santos et al. (2017, p. 2):

[...] estes significados podem ser desenvolvidos tendo como ponto de partida o significado inicial atribuído pelo aluno às atividades e ao discurso do professor relativo ao conhecimento que está sendo abordado, tornando necessários momentos em que ocorram em sala de aula processos interativos e reflexivos.

Deste modo, manifesta-se a necessidade de analisar como os alunos entendem o discurso do professor, se eles atribuem ou não algum significado que favoreça na assimilação e na construção dos significados que os possibilitem a aprendizagem matemática.

Quando o professor de matemática realiza interações verbais na sala de aula, interações estas que são marcadas pelo caráter dialógico, ele pode oferecer elementos para que os alunos possam entender e interpretar os acontecimentos que compõem a sala de aula. Estes elementos podem ajudar na análise de como os discursos realizados pelo professor são compreendidos pelos alunos.

Estudar o diálogo entre professor e alunos pode oferecer uma percepção de quais situações de interações discursivas, na sala de aula, contribuem para a compreensão do discurso do professor pelos alunos. De acordo com Tavares (2004), na sala se aula de matemática, os enunciados verificados, em algumas ocasiões, por meio da língua materna ou por meio de símbolos (ou uma relação entre a língua materna e estes símbolos), são verbalizados pelo professor ou pelos alunos. O mesmo ainda afirma que cada palavra adquire um novo significado quando este é partilhado por esses interlocutores. 
Os alunos precisam interagir entre si, e estes precisam interagir com o professor, para que ocorra assim uma troca de informações, possibilitando um maior conhecimento. Para que ocorram processos interativos em que o aluno seja provocado para o debate dependemos do discurso do professor. O debate só será produtivo se for possível ao aluno o desenvolvimento da compreensão do discurso do professor, o levando a uma atribuição de significado. A partir do discurso do professor, o aluno terá a oportunidade de estudar, analisar e formular os conceitos produzidos por influência de tal discurso.

Um estudo de Barboza (2011), em uma situação onde estudam o conteúdo de ângulos, analisa como os alunos do ensino fundamental compreendem o discurso do professor de matemática em sala de aula. No estudo foram encontradas situações de interação em sala de aula em que o discurso do professor favorece a compreensão pelo aluno. $\mathrm{O}$ autor em suas conclusões afirma, por exemplo, que situações em que o professor negligencia a linguagem matemática ou situações em que o professor faz um discurso realizando comparações entre entes matemáticos favorecem a aprendizagem pelo aluno.

\section{Análise dos dados}

Os episódios foram extraídos entre as 20 aulas gravadas. Foi observada uma sequência de aulas durante três semanas não consecutivas em cada sala de aula. Em ambas as salas, os conteúdos ministrados eram o de função afim e o de função quadrática. A pesquisa foi realizada em duas escolas públicas estaduais localizadas nas cidades de Ingá e Campina Grande, no estado da Paraíba.

\section{Episódio 1:}

Apresentamos, a seguir, os diálogos do professor A com os alunos, quando iniciava o conteúdo de função do primeiro grau:

Professor A: Então vamos dar continuidade ao assunto. Agora irei colocar no quadro alguns exemplos de funções do primeiro grau, e quero que vocês me digam quem vai ser o número real $a$ e quem vai ser o número real $b$, certo?

Aluno 1: Mas, professora, como eu vou saber quem vai ser $a$ e quem vai $\operatorname{ser} b$ ?

Professor A: Vocês lembram que no $9^{\circ}$ ano vocês estudaram Equação do $2^{\circ} \mathrm{Grau}$ ? 
Aluno 2: Eu lembro. Que tinha a letra x com um dois em cima.

Aluno 3: Era x elevado a dois.

Aluno 1: Ah, eu lembro sim.

Professor A: Vocês lembram que o número $a$ era aquele que acompanhava $\mathrm{o} \mathrm{x}^{2}$, o número $b$ o que acompanhava o $\mathrm{x}$ e o número $c$ era o que ficava sozinho?

Aluno 1: Eu me lembro.

Aluno 4: Eu também lembro.

Professor A: O resto da turma lembra? (Os alunos respondem quase a uma só voz, afirmando que sim).

Professor A: Na função do primeiro grau iremos fazer a mesma coisa. Se a gente prestar atenção na definição, vamos ver que o número $a$ vai ser àquele que acompanha o x e o número $b$ vai ser o que está sozinho. Olhem aqui. (Aponta para a definição no quadro).

Aluno 1: É mesmo! Não tinha prestado atenção nisso. Agora está fácil. Pode encher o quadro que eu respondo tudo (Todos da sala riram).

Professor A: Então vou colocar aqui três exemplos e quero que todos respondam quem vai ser $a$ e quem vai ser $b$. Não é pra responder no caderno. Quero uma resposta coletiva, certo? (O professor escreve as seguintes funções no quadro: $f(x)=2 x+1, f(x)=-x+4$ e $f(x)=4 x$. Quem vai ser $a$ e quem vai ser $b$ nessa função aqui? (Aponta para a função $f(x)=2 x+1)$.

Aluno 5: O $a$ vai ser $2 \mathrm{x}$ e o $b$ vai ser 1 .

Professor A: Olha, gente! Quando vamos dizer quem são $a$ e $b$, dizemos apenas os números, o x a gente não fala. Entenderam? Aqui o $a$ não vai ser $2 \mathrm{x}$, vai ser apenas o 2 , pois colocamos apenas o número, certo? O $b$ está certo, vai ser 1 .

Aluno 5: Ah, entendi!

Podemos observar que o professor A recorre a um discurso realizando uma comparação que, em primeiro instante, parece não fazer sentido, pois ele compara a função do $1^{\text {o }}$ grau com a equação do $2^{\circ}$ grau. Podemos até afirmar que, desse modo, o professor A não leva em consideração o rigor da linguagem matemática. Entretanto, pela reação dos alunos, ao afirmarem que lembram, quando o professor A fez a comparação, facilitou a compreensão, ou 
seja, a aprendizagem.

Os alunos se posicionam respondendo que lembram do conteúdo perguntado pelo professor A, e que foi o elemento desencadeador para a compreensão do que estava sendo estudado. Segundo Bakhtin (2003), na comunicação discursiva, o ouvinte quando compreende o significado linguístico do discurso, "concorda ou discorda dele (total ou parcialmente), completa-o, aplica-o, prepara-se para usá-lo, etc.; essa posição responsiva do ouvinte se forma ao longo de todo o processo de audição e compreensão desde o seu início, às vezes, literalmente a partir da primeira palavra do ouvinte” IBID (2003, p. 271). Tendo como base as palavras de Bakhtin, entendemos que os alunos ocupam uma posição responsiva em relação ao discurso realizado pelo professor A.

Bakhtin (2006) afirma que a compreensão é uma forma de diálogo, e que ela está para a enunciação do mesmo modo que uma réplica está para outra no diálogo. Diálogos e réplicas entre o professor A e os alunos são observados. Então, compreensão e significação estão presentes, Bakhtin (2006, p. 137) reforça, “a significação pertence a uma palavra enquanto traço de união entre os interlocutores, isto é, ela só se realiza no processo de compreensão ativa e responsiva". Deste modo, a significação e a compreensão são verificadas nas interações entre os interlocutores. A fala do Aluno 1 é representativa, "É mesmo! Não tinha prestado atenção nisso. Agora está fácil. Pode encher o quadro que eu respondo tudo".

\section{Episódio 2:}

Observamos os seguintes diálogos entre o professor A e seus alunos após explicar como se constrói o gráfico da função quadrática e pedir que os alunos, de forma conjunta, o ajudassem a construir um gráfico:

Professor A: Então vamos construir o gráfico da função $f(x)=x^{2}+5 x$ +4. Todos juntos, certo? Vamos lá. O que devemos fazer primeiro?

Aluno 1: Construir a tabelinha com x e o y.

Professor A: E como vai ficar?

Aluno 1: Coloca x de um lado, a função no meio e o y do outro. Aí a gente diz que $\mathrm{x}$ vai ser $-2,-1,0,1$ e 2 .

Professor A: Muito bem! Continue.

Aluno 1: Agora a gente troca onde for $x$ por -2 . E acha o y.

Aluno 2: Eu posso dizer como vai ficar?

Professor A: Pode. Diga.

Aluno 2: Vai ficar -2 ao quadrado mais 5, que multiplica -2, mais 4. 
Aí fica $4-10+4.4-10$ é $-6,-6+4$ dá -2 . Então x é -2 e o y também.

Professor A: Isso mesmo. Vamos continuar. Agora quando o x é -1 . Qual vai ser o valor de y?

Aluno 3: -1 elevado a 2 mais 5 vezes -1 , mais 4 . Fica $1 \ldots-5+4$. Acho que vai ser zero, né, professora?

Professor A: Dá zero mesmo. Ou seja, quando x é -1 o valor da nossa função, ou o nosso y, será zero. Entenderam? Agora para x igual a zero, o que vamos ter?

Aluno 2: Esse é fácil, vai ser 4.

Professor A: Tu já tá craque, né?

Aluno 2: Mas aí não tem como errar. Se o x vai ser zero, então o x ao quadrado e o 5x também é zero. Só vai sobrar o 4.

Professor A: Isso mesmo. Então quando x é zero, y é 4. Aí já coloca o valor aqui na tabelinha pra não esquecer. Vamos pra o próximo valor de $\mathrm{x}$, que vai ser 1 . Quando x é 1 o y vai ser?

Aluno 1: Fica $1+5+4$, que dá 10. E quando for 2 fica $4+10+4$, que dá 18.

Professor A: Olha. Parabéns!

Observamos que os alunos compreenderam a explicação e o conteúdo dado pelo professor A, pois conseguiram construir o gráfico sem que demonstrassem dificuldades. Podemos observar também que o professor A, em suas interações dialógicas com os alunos, utilizou, na maioria das vezes, o ato da pergunta, e os alunos, de acordo com Bakhtin (2006), formularam palavras próprias para responder as indagações feitas pelo professor A.

Ao estudar as interações em sala de aula, Englund (2006) afirma que essas interações são averiguadas por meio da comunicação, como uma tentativa de possibilitar, para cada aluno, a capacidade de assumir uma posição de escuta, deliberação, busca por argumentos e avaliação, de modo que, ao mesmo tempo, haja um esforço coletivo entre os alunos para encontrar valores e normas em que todos possam concordar.

Para que se possa estabelecer as condições discursivas, o papel do professor se torna essencial. Para Englund (2006), o professor deve ser o responsável por possibilitar o surgimento das possíveis práticas de comunicação, gerando assim uma situação discursiva na sala de aula. 


\section{Episódio 3}

Em outra sala de aula, no momento da aula a seguir, é apresentado um diálogo do professor B com os seus alunos ao explicar sobre a concavidade da parábola do gráfico de uma função quadrática:

Professor B: Quando eu olho pra cá (o professor aponta para uma função do segundo grau que está escrita no quadro), para o valor do $a$, eu terei noção se a concavidade da parábola será voltada para cima ou voltada para baixo. (P.S. Os alunos se entreolham, demonstrando não terem compreendido o que o professor acabara de falar. Notando isto, o professor desenha no quadro duas carinhas, uma feliz e outra triste, e as usa para explicar o que foi falado por ele anteriormente).

Professor B: Se o $a$ for maior que zero, então a concavidade da parábola será voltada para cima (aponta para a carinha feliz desenhada no quadro) e se o $a$ for menor que zero então a concavidade da parábola será voltada para baixo (aponta agora para a carinha triste desenhada no quadro). Entenderam? (Os alunos respondem em voz alta, que sim).

Podemos observar que o professor B abriu mão de uma linguagem matemática mais formal, buscando uma saída para a falta de compreensão dos alunos, e fez uso de desenhos para que pudesse alcançar a compreensão do que por ele foi explicado pela maioria dos alunos. A afirmação pode ser observada quando ele aponta para as carinhas desenhadas no quadro para diferenciar a concavidade da parábola voltada para cima da concavidade da parábola voltada para baixo.

O discurso realizado pelo professor B relativizando o rigor da linguagem matemática ao relacionar desenhos comuns com o conteúdo de função quadrática traz algumas implicações. Segundo D’Amore (2007), isso expressa uma contradição da linguagem específica. Para o autor, um dos objetivos da comunicação é o de favorecer a aprendizagem dos alunos, então, o professor deve se comunicar de forma que a linguagem utilizada não seja um obstáculo para a compreensão dos alunos. Porém “a matemática possui uma linguagem específica (ou até mesmo é uma linguagem específica)" (D’AMORE, 2007, p.249). Assim, o professor tem como desafio fazer uso de uma linguagem que favoreça a compreensão dos alunos e, ao mesmo tempo, ter o cuidado de fazer com que os alunos aprendam a linguagem específica da matemática. 


\section{Entrevista com os professores}

No Final de algumas aulas, perguntamos aos professores: O que você acha do discurso que realiza na sala de aula, pensando na compreensão do aluno? Obtivemos a seguinte resposta do professor A:

Eu acho que realizo um discurso de forma compreensível, pois utilizo acontecimentos do cotidiano dos alunos para tentar explicar da melhor maneira possível o conteúdo, de forma que eles possam assimilar o que eu expliquei de uma maneira simples e fácil (PROFESSOR A).

Já o professor B se posicionou assim:

Procuro sempre ter um discurso em sala de aula que seja motivador, porém deixando claro que tudo exige esforço para se conseguir, principalmente no estudo da matemática (PROFESSOR B).

Perguntamos ao professor A: Por qual motivo você acha que existe dificuldade ou facilidade em o aluno compreender o seu discurso? A resposta foi a seguinte:

Eu percebo que o nível de interesse em aprender entre os meus alunos é variado. Alguns dos meus alunos apresentam facilidade em compreender o meu discurso, facilidade essa que decorre da base escolar que os mesmos tiveram, porém outros apresentam uma maior dificuldade em compreender os conteúdos, pois não possuem interesse na aula, nem apresentam expectativas para o futuro escolar. A maioria desses alunos são repetentes, e eu acho que isso acaba gerando entre eles um certo desestímulo, de modo que eles acabam desestimulando os alunos novatos (PROFESSOR A).

Já para o professor B, perguntamos: Por que escolheu esse discurso para ministrar suas aulas? Ele nos respondeu:

Pelo fato de ter tido muita dificuldade em matemática e hoje sei que muito do que se pode aprender depende do interesse do aluno e também de um pouco de motivação do professor já que o intuito não é formar vários matemáticos e sim fazer com que o aluno tenha a noção da importância da matemática no seu dia a dia (PROFESSOR B).

É notável que o professor B afirma que realiza um discurso motivador, mas o que foi observado em sala de aula aponta em uma direção oposta a essa afirmação. O professor pareceu motivado, mas o mesmo não pode ser afirmado em relação a um discurso nessa direção. Um professor que parece motivado é diferente de um professor que realiza um 
discurso motivador.

Nas aulas do professor A ocorreram situações que, de certo modo, trouxeram implicações no processo de compreensão dos alunos, pois o mesmo realizou um discurso buscando fazer comparações que, mesmo relativizando o rigor da linguagem matemática, favoreceu a compreensão dos alunos.

Segundo Bakhtin (2003), os diferentes gêneros discursivos implicam em diferentes diretrizes de objetivos, ou projetos de discurso dos falantes, "o empenho em tornar inteligível a sua fala é apenas o momento abstrato do projeto concreto e pleno do discurso do falante" (BAKHTIN, 2003, p. 272). O autor do discurso não é apenas um falante, ele é também um respondente, independentemente da situação. Tanto o professor como os alunos são falantes e respondentes; tanto verbalizam os seus gêneros discursivos, como ocupam uma posição ativa de resposta.

\section{Considerações finais}

A análise das interações em sala de aula entre o professor e o aluno é algo fundamental, pois o discurso do professor é um dos fatores que podem interferir na compreensão do aluno. Dependendo do discurso do professor, podem ocorrer processos interativos em que o aluno é provocado para o debate, e este somente será produtivo se o aluno desenvolver uma compreensão do discurso do professor que o leve a uma atribuição de significado.

Na sala de aula, tanto o professor quanto o aluno buscam ser compreendidos um pelo outro, mas nem sempre essa compreensão é alcançada, pois muitas vezes o aluno não consegue entender a linguagem matemática utilizada pelo professor, e isso dificulta para que o aluno possa argumentar e elaborar questionamentos. Consideramos que nesse processo é preciso levar em consideração as construções elaboradas pelos alunos, seja por meio do auxílio do professor, ou evidenciadas pela espontaneidade e originalidade das suas respostas. Essas respostas podem ser reveladoras de uma posição espontânea ou fruto de uma compreensão anterior.

O discurso do professor é de suma importância para que o aluno compreenda o conteúdo, não só na disciplina de matemática, mas também em todas as outras. É através do discurso do professor que o aluno cria o seu próprio discurso.

Durante o período de gravações das aulas percebemos que não houve situações em que os professores tenham provocado os alunos para o debate, ou seja, para as interações com os 
colegas e a participação na sala de aula, mas é possível afirmar que nos momentos que foram destacados nos resultados da pesquisa, ocorrem situações que podem, de alguma forma, implicar no processo de compreensão dos alunos, pois o professor A buscou realizar um discurso onde o mesmo faz comparações entre conteúdos de anos diferentes, para que os alunos pudessem absorver de uma melhor forma o conteúdo que ela queria transmitir e deste modo, mesmo relativizando o rigor da linguagem matemática, favoreceu a compreensão dos alunos. Além disso, também observamos que o professor B afirma realizar um gênero discursivo, no entanto, o gênero discursivo observado não corresponde ao que o mesmo afirma realizar.

Outras pesquisas precisam ser empreendidas na área do discurso, talvez até repetidas com outros participantes. Um aspecto ainda carece de maiores esclarecimentos, trata-se de como o professor de matemática se refere ao discurso que realiza ou a percepção que tem do próprio discurso.

\section{Referências}

ALMEIDA, J. J. P. Gêneros do discurso como forma de produção de significados em aulas de matemática. Campina Grande: Eduepb; São Paulo: Livraria da Física, 2016.

BAKHTIN, M. Estética da criação verbal. 4 ed., São Paulo: Martins Fontes, 2003.

BAKHTIN, M. Marxismo e filosofia da linguagem: problemas fundamentais do método sociológico da linguagem. Tradução Michel Lahud e Yara Frateschi Vieira. 12a ed., São Paulo: Hucitec, 2006.

BARBOZA, P. L. Compreensões do discurso do professor de matemática pelos alunos. Salvador: Universidade Federal da Bahia, 2011. (Tese de Doutorado na Área de Ensino, Filosofia e História das Ciências).

BARBOZA, P. L; RÊGO, R. M; BARBOSA, J. C. Trilhas para a análise da compreensão do discurso do professor pelos alunos. Revista Paranaense de Educação Matemática. Campo Mourão, Pr, v.3, n.5, jul.-dez, 2014, p. 50-72.

CARVALHO, C. Comunicações e interações sociais nas aulas de matemática. In: LOPES, A. 
E. NACARATO, A. M. (Orgs.). Escritas e leituras na educação matemática. Belo Horizonte: Autêntica, 2009.

COBB, P. Individual and collective mathematical development: the case of statiscal data analysis. Mathematical Thinking and Learning, 1, 5-43, 1999.

D’AMORE, B. Elementos de didática da matemática.Tradução Maria Cristina Bonomi. São Paulo: Editora Livraria de Física, 2007.

DAVIDSON, N. Cooperative learning in mathematics. S. Francisco: Addison-Wesley, 1990.

DENZIN, N. K; LINCOLN, Y. S. A disciplina e a prática da pesquisa qualitativa. In: DENZIN, N. K; LINCOLN, Y. S. O planejamento da pesquisa qualitativa: teorias e abordagens. Porto Alegre: Artmed, 2005.

ENGLUND, T. Deliberative communication: a pragmatist proposal. Journal Curriculum Studies, vol. 38, $\mathrm{n}^{\circ}$ 5, p. 503-520, 2006.

FADEL, F. T. B. de A. Variações do discurso na sala de aula de matemática. 2008. 128f. Dissertação (Mestrado), Belo Horizonte: Universidade Federal de Minas Gerais. 2008.

FIORENTINI, D. Alguns modos de ver e conceber o ensino da Matemática no Brasil. Zetetiké. Ano 3, n.4, p. 01-37, Campinas, SP, 1995.

INNES, R. B. Dialogic communication in collaborative problem solving groups. International Journal for the Scholarship of Teaching and Learning. Vol. 1, $\mathrm{n}^{\mathrm{o}}$ 1, 2007.

JANSEN, A. An investigation of relationships between seventh-grade students' beliefs and their participation during mathematics discussions in two classrooms. Mathematical Thinkingand Learning, v. 10, p. 68-100, 2008.

MONTEIRO, A.; NACARATO, A. M. relações entre saber escolar e saber cotidiano: apropriações discursivas de futuros professores que ensinarão matemática. Bolema, ano 
17, no 22, p. $1-17,2004$.

MONTEIRO, V. M. Relação entre o discurso do professor de matemática e a compreensão do aluno. 2014. 26 f. Trabalho de Conclusão de Curso (Graduação) Universidade Estadual da Paraíba, Campina Grande, 2014.

MARTIN, L.; TOWERS, J.; PIRIE, S. Collective mathematical understanding as improvisation. Mthematical Thinking Learning, v. 8, nº 2, p. 149-183, 2006.

PIMM, D. El lenguaje matemático en el aula. Madrid: Morata. 1990.

PONTE, J. P. et al. A comunicação nas práticas de jovens professores de matemática. Revista Portuguesa de Educação, v. 20, nº 2, Braga - Portugal, 2007.

SFARD, A.; KIERAN, C. Cognition as communication: rethinking learning-by-talking through multi-faceted analysis of student's mathematical interactions. Mind, Culture, and Activity, v. 8, no 1, p. 42-76, 2001.

SANTOS, V. M. Linguagens e comunicações na aula de matemática. In: NACARATO, A. M; LOPES, C. E. Escritas e leituras na educação matemática. Belo Horizonte - MG: Autêntica, 2009.

SANTOS, J. G. L; PONTES, J. L; SILVA, R. J. F; BARBOZA, P. L.Relação entre a aprendizagem matemática e o discurso do professor. In: IV SIMPÓSIO NACIONAL DE LINGUAGENS E GÊNEROS TEXTUAIS, 2017, Campina Grande - PB. Anais... Campina Grande: Realize, 2017.

TAVARES, C. F. S. Linguagem e Significação: uma análise da interação discursiva na sala de aula de matemática. 2004. 175f. Dissertação (Mestrado). Belo Horizonte: Universidade Federal de Minas Gerais, 2004.

VACCARI, B. V. A interação na sala de aula de matemática. Dissertação (Mestrado). ULBRA, 2007. 


\section{Res., Soc. Dev. 2019; 8(3):e3083790}

ISSN 2525-3409 | DOI: http://dx.doi.org/10.33448/rsd-v8i3.790

WATSON, J. M.; CHICK, H. L. Factors influencing the outcomes of collaborative mathematical problem solving: an introduction. Mathematical Thinking and Learning, vol. $3, \mathrm{n}^{\mathrm{o}} 2$, p. 125-173, 2001. 